\title{
La reconfiguración de las luchas afro en San Lorenzo (Ecuador) frente a la expansión de la palma aceitera y la transnacionalización del conflicto colombiano ${ }^{2}$
}

\author{
The Reconfiguration of Afro Struggles in San Lorenzo (Ecuador) Against Oil \\ Palm Expansion and the Transnationalization of the Colombian Conflict \\ A reconfiguração das lutas afro em San Lorenzo (Equador) em frente à expansão \\ da palmeira de óleo e a transnacionalização do conflito colombiano
}

\begin{abstract}
Resumen
El artículo pretende evidenciar cómo la expansión de la palma aceitera implica también la del paramilitarismo colombiano a nivel transnacional. Se enfoca en la región norte de la provincia de Esmeraldas (Ecuador), la cual hace parte de la región del Chocó biogeográfico, que se extiende a Nariño, Cauca, Chocó (Colombia) y llega hasta el sur de Panamá. En esta región confluyen condiciones estructurales de discriminación, pobreza, exclusión y violencia que afectan a las poblaciones afrodescendientes y sus formas de organización, circunstancias que favorecen la presencia de actores armados, rutas de narcotráfico y expansión de cultivos de palma aceitera. Para entender este fenómeno de violencia y acumulación capitalista se debe recurrir a las nociones de acumulación por desposesión y economías criminales, todo ello analizado desde el marco de la colonialidad del poder.
\end{abstract}

Palabras clave: Palma aceitera, economía ilegal, paramilitarismo, colonialidad del poder, Ecuador.

\section{Recibido: 12 de mayo, evaluado: 11 de junio, aprobado: 12 de junio}

1 Docente Universidad Distrital Francisco José de Caldas. Magíster en Sociología de la Facultad Latinoamericana de Ciencias Sociales, Flacso, sede Ecuador, candidato a Magíster en Integración Regional de la Universidad Andina Simón Bolívar, Sede Ecuador. Correo electrónico: bramwen@gmail.com

2 Esta investigación se origina a partir de la realización de la monografía de grado El desborde de la violencia: raza, capital y grupos armados en la expansión transnacional de la palma aceitera en Nariño y Esmeraldas. Continúa con la realización del estudio de Save the Children La situacion de NNA en contextos de movilidad humana y actividades extractivas en los cantones de San Lorenzo y Eloy Alfaro y finaliza con la investigación titulada "Seguimiento a las dinámicas del conflicto armado en la frontera Colombo-Ecuatoriana". 


\begin{abstract}
The article aims to show how the expansion of oil palm also implicates the Colombian paramilitarism at a transnational level. It focuses on the northern region of the province of Esmeraldas (Ecuador), which is part of the biogeographic Chocó region which extends through Nariño, Cauca, Chocó (Colombia) and reaches the south of Panama. In this region convergent structural conditions of discrimination, poverty, exclusion and violence affect Afro-descendant populations and their forms of organization. Such circumstances favor the presence of armed actors, drug trafficking routes and expansion of oil palm crops. In order to understand this phenomenon of violence and capitalist accumulation, it is necessary to recur to the notions of accumulation by dispossession and criminal economies analyzed from the perspective of the coloniality of power.
\end{abstract}

Keywords: Oil palm, illegal economy, paramilitarism, coloniality of power, Ecuador.

\title{
Resumo
}

$\mathrm{O}$ artigo pretende evidenciar como a expansão da palmeira-de-dendê implica também a do paramilitarismo colombiano a nível multinacional. Foca-se na região norte da província de Esmeraldas (Equador), a qual faz parte da região do Chocó bio-geográfico, que se estende a Nariño, Cauca, Choco (Colômbia) e chega até o sul de Panamá. Nesta região confluem condições estruturais de discriminação, pobreza, exclusão e violência que afetam às populações afro-descendestes e suas formas de organização, circunstâncias que favorecem a presença de rotas de narcotráfico e expansão de cultivos de palmeira-de-dendê. Para entender este fenômeno de violência e acumulação capitalista, deve ser recorrido às noções de acumulação por desapropriação e economias criminosas, todo isso analisado a partir do marco da colonialidade do poder.

Palavras-chave: Palmeira-de-dendê, economia ilegal, paramilitarismo, colonialidade do poder. 
La investigación realizada por cuatro años da cuenta de una realidad compleja en la región norte de Esmeraldas en los cantones de Eloy Alfaro y San Lorenzo (Ecuador). Los problemas que confluyen en la región son la minería, las plantaciones de palma, la pérdida de territorios de comunidades afrodescendientes, la presencia de bandas 'sicariales' y de grupos armados colombianos. Estos últimos trajeron el narcotráfico a la región y tecnificaron el ejercicio de la violencia, a través de una economía ilegal, que sentó sus bases sobre el tráfico de gas y gasolina, la extracción de oro, el narcotráfico y los préstamos 'gota a gota'. Esta problemática se debe a la poca presencia del Estado ecuatoriano en la región y a la creencia de que la zona se encuentra en la periferia, habitada en su mayoría por afrodescendientes, teniendo como consecuencia un racismo estructural visible, el cual es ejercido tanto por el Estado como por el conjunto de la sociedad ecuatoriana. El conflicto colombiano potencia las problemáticas y permite entender el recrudecimiento de la violencia en momentos determinados en la región, como el aumento sustancial de los cultivos de palma entre 2007 y 2010.

En el norte de Esmeraldas confluyen tres grandes sistemas: el capital, la raza y la violencia. Es importante aclarar que históricamente, desde la época colonial hasta la conformación del Estado nacional ecuatoriano, el desarrollo del capital en la región es extractivista. La minería y la trata de esclavos hacen parte de la explotación económica de Esmeraldas desde el siglo XVII, continuando en el periodo postindependentista cuando Ecuador tuvo que, debido a la deuda de la independencia con el gobierno británico:

Pagar el 21 por ciento de la deuda total contraída, suscribió en 1854 un contrato con los acreedores británicos para pagarles 'con terrenos baldíos y su producto' en la costa y la Amazonia. Fue así como en 1857 se adjudicaron a la compañía británica Ecuador Land Company, por un periodo de cien años, a un precio irrisorio y libre de toda clase de impuestos, extensos territorios en la provincia de Esmeraldas. La compañía se dedicó a la explotación de tagua, madera, oro [...] así, después de haber sido liberada de la corona española, Esmeraldas pasaba a ser una suerte de colonia de la corona británica. (Arboleda 2005, p. 107).

María Victoria Arboleda considera que este acto del naciente Estado ecuatoriano sería muestra de "[...] un patrón de abandono y negligencias al que posteriormente estaría sometida la provincia" (2005, p. 107). De esta manera, el Estado se desentiende de las decisiones de una parte del territorio nacional, puesto que "[...] se entregaron títulos de propiedad sobre una extensión de 200.000 cuadras cuadradas, en San Lorenzo y Atacames, [...] así se creó una situación que en nada benefició a la provincia y devino más bien en una pesada carga" (Jaramillo et al., 1981, p. 25).

Con el confinamiento de la población afroesmeraldeña a los designios de la compañía, se le suma que:

La compañía emitió su propia moneda -el pailón- con la cual se hacían todas las transacciones comerciales en el área, desconociendo así el artículo del convenio que mandaba a reconocer la soberanía del Ecuador sobre los terrenos y sus poblaciones [...] los derechos concedidos a la Ecuador Land Company pasaron a la Compañía alemana Casa Tagua s. A. alrededor de 1907 y fueron reintegrados al gobierno ecuatoriano en 1937. (Arboleda, 2005, p. 108).

Lo anterior evidencia la ausencia casi total del Estado ecuatoriano en esta región, su debilidad en el territorio y su sentido de lejanía; de allí que "su vinculación física comienza recién en 1948 con la inauguración de la carretera Santo DomingoQuininde; diez años más tarde, en 1958, con la inauguración del ferrocarril Ibarra-San Lorenzo y solo en la década de los 60 , con la carretera Esmeraldas-Quininde-Santo Domingo-Quito" (Jaramillo et al., 1981, p. 23). Entonces, repasando la historia, son claros los fines económicos que ha tenido la región y que permanecen con el auge del banano y el boom petrolero, en la década de los cincuenta, la madera en los noventas y la palma aceitera desde el siglo XxI. 
El segundo sistema es la raza, que desde Aníbal Quijano es entendido como un patrón de poder colonial presente históricamente en las formaciones capitalistas:

La colonialidad es uno de los elementos constitutivos y específicos del patrón mundial de poder capitalista. Se funda en la imposición de una clasificación racial/ étnica de la población del mundo como piedra angular de dicho patrón de poder y opera en cada uno de los planos, ámbitos y dimensiones, materiales y subjetivas, de la existencia social cotidiana y a escala societal. (Quijano. 2000, p. 342).

Desde esta perspectiva se puede entender por qué el capitalismo que se emplaza en esta región a lo largo de sus diferentes fases de acumulación ha hecho que la región norte de Esmeraldas sea vista como una región periférica, de la cual se puede extraer toda su riqueza sin tener en cuenta a la población afro que allí habita, sumado a ello la Nación "imagina" ${ }^{3}$ este espacio como alejado del resto del Ecuador. Los procesos de acumulación que el capital ha desarrollado con base en el patrón de poder racial se pueden ver en las diferentes dinámicas que ha tomado el capital en la región, primero de manera esclavista-extractivista y segundo extractivista-coercitiva y violento.

A través del patrón de poder racial presente en el capitalismo desde sus orígenes, se puede entender la continuidad del mismo en el capitalismo avanzado o neoliberal, lo que quiere decir que las regiones construidas en los márgenes de los Estados nacionales o los espacios periféricos se convierten en los centros de desarrollo del capitalismo neoliberal colonial violento. En consecuencia, el desarrollo del neoliberalismo en la región periférica de Esmeraldas asume una estructura violenta y desposesiva (no se podría entender la acumulación por desposesión ${ }^{4}$ en la región de Esmeraldas, si no se entiende la construcción periférica y racializada que se ha hecho de la región). Por último, la realidad compleja del norte de Esmeraldas no se puede leer sin tener en cuenta que la violencia estructural e histórica (el tercer sistema de comprensión) que se ha desarrollado en la región ha venido unida al avance del capital tanto legal como ilegal y está fundamentada en el patrón de poder racial, de ahí que este espacio del capital solo se puede entender bajo esta trinidad: capital, raza y violencia.

La violencia, como se dice anteriormente, se puede entender como un elemento estructural e histórico tangible en la pérdida del territorio ancestral afro, la explotación minera y el cultivo de palma, que se manifiesta en las amenazas a líderes opositores de la minería y la expansión de la palma. En este punto, el desarrollo del capital en la región ha estado anclado al uso de formas de violencia, no siempre visibles. Con la consolidación del paramilitarismo en la frontera el ejercicio de la violencia se hace más evidente, pero no es constante. En este sentido, Gayraud dice que:

La violencia pertenece a una etapa inicial de afirmación e instalación del poder mafioso, pero no es un elemento permanente, la reputación de peligrosidad, fruto de la historia y el mito, basta de originario para extender el miedo, el temor generalizado permite economizar y evitar el uso de la violencia. (2007, p. 258).

El uso dosificado y limitado de la violencia a casos específicos permite al capital criminal reproducirse en un territorio determinado y obedece “[...] a tres criterios. Es económica, invisible y endógena" (Gayraud, 2007, p. 258). Por esto:

3 En este punto me refiero al concepto de comunidades imaginadas de Benedict Anderson (1993).

4 Una mirada más atenta de la descripción que hace Marx de la acumulación originaria revela un rango amplio de procesos. Estos incluyen la mercantilización y privatización de la tierra y la expulsión forzosa de las poblaciones campesinas; la conversión de diversas formas de derechos de propiedad común, colectiva, estatal, etc., en derechos de propiedad exclusivos; la supresión del derecho a los bienes comunes; la transformación de la fuerza de trabajo en mercancía y la supresión de formas de producción y consumo alternativas; los procesos coloniales, neocoloniales e imperiales de apropiación de activos, incluyendo los recursos naturales; la monetización de los intercambios y la recaudación de impuestos, particularmente de la tierra; el tráfico de esclavos; y la usura, la deuda pública y, finalmente, el sistema de crédito (Harvey, 2004, p. 113). 
[...] las mafias prefieren estrategias de baja visibilidad que practican un control estricto de la violencia, la utilización de la violencia está regulada y dosificada [...] con la violencia, una mafia queda al descubierto, se coloca en el punto de mira de la policía y los medios de comunicación. (Gayraud 2007, p. 258).

En este sentido, se puede entender porque el ejercicio de la violencia, con todas sus consecuencias, no es concebido como un factor estructural perceptible, sino por el contrario, ubicado, endógeno y controlable.

Teniendo clara tanto la triada capital, raza y violencia como su incidencia en la expansión de la palma aceitera en la región norte de Esmeraldas, ahora se enuncia cómo se ha atentado de manera violenta contra el territorio afro y las formas de vida, desde la 'omisión' del Estado ecuatoriano y la expansión del capital.

\section{La organización social y la resistencia histórica en el norte de Esmeraldas}

Desde los años setenta, el origen de las organizaciones sociales en Esmeraldas se da a partir de los continuos enfrentamientos a las problemáticas de la región. Según Juan García, los primeros líderes que surgen en esa década hasta los noventa son considerados 'líderes espirituales', ya que el impulso por la organización no pretendía tener réditos económicos:

Los noventas desde los años setentas, esos 20 años, el mismo Juan García lo dice, los líderes de esta época eran líderes espirituales, que quiere decir, el líder espiritual es aquel que hace un servicio gratuitamente. El cabildo de la comuna río Cayapas-Santiago, para decirte, no recibía plata, era elegido y hacia un servicio a la comuna, buscando fondos o buscando arreglar los problemas internos, pero un servicio gratuito, hoy este servicio es pagado, pagado por las multinacionales, por las tierras, por la venta de madera, por aquí, por allá. (Comunero de la región norte de Esmeraldas, Ecuador, 2011).
El proceso organizativo que venía de la década del setenta se vio truncado por la llegada de las madereras, las cuales "[...] entraron en la comuna hasta los años 1993, 1994, ahí empezaron, hasta los años noventa" (comunero de la región norte de Esmeraldas, Ecuador, 2011). En ese entonces, el presidente de la comuna permitió la entrada de las madereras a las comunas a cambio de recibir réditos económicos, legado que ha quedado en los presidentes comunales desde entonces.

El desarrollo del capital en la región ha demarcado los destinos de los pobladores afros de la comuna, todo ello permitido por los dirigentes que carecían de la vocación de la que habla Juan García. Posteriormente a la entrada de compañías extractivas se dio la entrada de las ONG y de dinero en los sistemas organizativos a la región. Esto llevó a un replanteamiento en el sistema y lo volvió un ejercicio lucrativo.

La organización social en la región no fue alterada en su totalidad, pero sí permite plantear elementos que dan cuenta de su actual crisis. El proceso organizativo de larga data ha permitido que pervivan elementos para sostener las estructuras organizativas que aún no han sido afectadas por el lucro. En la genealogía del proceso organizativo es donde se puede entender la persistencia de elementos para su continuidad:

El proceso comenzó acá en Borbón con la organización de la Ocame (Organizaciones campesinas de Muisne Esmeraldas), que se alió con la Ocame que estaba en Muisne, una organización campesina, [...] ellos en el 83 estaban fundados sobre cuatro ramas o cuatro partes: 1. Los promotores de salud, había en cada pueblito una persona escogida por la comunidad, que, con las doctoras del movimiento laico de América Latina, con el vicariato, formaron para que estuviera presente un pequeño botiquín en cada comunidad. Después, había la rama de los padres de familia para la educación Apafae. Ellos organizaban todas las comunidades para luchar para que el profesor trabajara dando clase. Después, había la rama de los grupos de trabajo, que eran organizados con el FEP [...], donde daban pequeños préstamos y empezaban cultivaciones nuevas y programas nuevos. $\mathrm{Y}$ 
había la rama de los catequistas, que era la rama que más antigua era, porque aquí (en la rama catequista) comenzaron los cursos de capacitación de los líderes. (Comunero de la región norte de Esmeraldas, Ecuador, 2011).

No solo se puede evidenciar el nivel organizativo, sino también los alcances y resultados del mismo a lo largo de los años noventa como lo fue la titulación de tierras. Como se mencionó anteriormente, fue con la entrada de las ONG como la organización social pasó de ser un elemento guiado por la vocación y la convicción a un elemento de lucro:

Las ONG venían de Quito una vez al mes acá de servicio y se iban, entonces ahí fue la gran infiltración de las madereras, de todo eso, que les ofrecían plata a todas las partes. La gente dejó las fincas para dedicarse a la madera, las grandes chocolateras se perdieron de esta forma, porque la gente comenzó a ir a donde sacaban plata, y ahí se desbarató todo. (Comunero de la región norte de Esmeraldas, Ecuador, 2011).

La presencia de las ONG se dio a nivel nacional, al igual que su incidencia en las organizaciones sociales, de ahí que los noventas hayan sido una década de grandes contradicciones, puesto que el capital se presentó de manera empresarial extractiva y en forma de ONG. Este contexto permite entender la entrada de la palma aceitera, cuyo proceso frustró la titulación de tierras en Esmeraldas, siendo este el último logro de la organización en los noventa:

Cuando nosotros terminamos los procesos de legalización de los territorios en el 94, 95 hasta el 96, terminamos la titulación en Carondelet, La Boca, Urbina, San Javier, terminamos el proceso y recién los manes ingresaron (refiriéndose a las palmicultoras), entraron atemorizando a la gente, ya en el 96, 97. En el 94 terminamos en Borbón (haciendo referencia a las titulaciones). En el 96, 97 comenzó la incursión de las palmeras, antes del 2000. Y nosotros terminamos las titulaciones con las justas, y como estábamos terminando el proceso de titulación y de entrega de escritura, empezaban a parecer los de las palmeras a hablarles de comprar las tierras. (Habitante de San Lorenzo, Esmeraldas, Ecuador, 2011).

La década del noventa fue el momento que marcó los elementos de declive organizativo de las comunidades afro en el norte de Esmeraldas y al mismo tiempo marcaría el destino de la región.

\section{El año 2000, primeros años de violencia organizada}

El año 2000 marca la expansión rotunda del cultivo de palma en la región norte de Esmeraldas, el cual pasa de tener 90 hectáreas en 1999 a tener 3795 al año siguiente. Fue en ese mismo año cuando se inició el proyecto expansionista de la palma y de la violencia, y en los años siguientes las comunidades ya daban cuenta de los estragos ambientales y sociales que traía la palma, como también de las primeras presiones violentas hacia los pobladores para vender las tierras:

Verás que en el 2000 es cuando ya se hizo el cambio de la moneda, la dolarización, entonces con la dolarización la gente colombiana, los grupos ilegales siempre tenían que ir a buscar el dólar fuera, a Estados Unidos, a Panamá. Con la dolarización el dólar ya lo tuvieron cerca, entonces todo ese desplazamiento permite que la zona comercial sea San Lorenzo. Entonces, los grupos guerrilleros iban a abastecerse a San Lorenzo, por eso en San Lorenzo la delincuencia y el sicariato era atroz, no tuvo otra salida el gobierno que potenciar las bases militares, y hacer el destacamento de la policía. Con eso se paró un poco este auge, y ya incluso en San Lorenzo se encontraron cientos de laboratorios, porque empezó a ser el Ecuador una zona de salida [refiriéndose al narcotráfico], ya con esas bases militares, la violencia se desplazó de San Lorenzo a Borbón, Borbón ahorita es el centro del 'sicariato'. [...] Sobre la palma, llamémosle así, de los ejemplos vivos de que la mayoría está financiada por el narcotráfico, de fondos ilegales que ha comprado grandes extensiones de tierra en San Lorenzo y que ahora maneja algunas grandes empresas, incluso parte de esos grupos ilegales es manejada por la palma, porque tienen gente que le brindan protección dentro del mismo cultivo, gente de allá [refiriéndose a los 
colombianos], gente desplazada, digamos que acá hay un potencial tanto económico como de grupos irregulares, de lo que conocemos. (Habitante zona norte de Esmeraldas, Ecuador, 2011).

Estos testimonios son insumo para entender, primero, el abandono del Estado hacia la región; segundo, el surgimiento de una economía irregular en la región (esta última se entiende por la aparición de los grupos armados colombianos); tercero, el surgimiento de una economía de la palma, que tiene como característica ser desposesiva y criminal y permitir el ingreso de nuevos actores en las dinámicas económicas como el narcotráfico y la obtención fraudulenta de tierras; y, por último, que la dolarización hizo que el Ecuador se convirtiera en un atractivo para la economía narcotraficante controlada por grupos armados colombianos y carteles mexicanos ('Zetas' y Sinaloa).

Para entender la inserción de las economías ilegales en la economía legal, es necesario entender los procesos de desregulación financiera que surgen con el neoliberalismo. Ello también erigió al dólar como la moneda de cambio para las transacciones ilegales. Bajo este panorama, el Ecuador desde el año 2000 se convierte en el espacio donde los dólares se pueden adquirir y lavar. Este fenómeno genera el lavado de dinero en San Lorenzo a través del presta diario, o préstamos 'gota a gota'.

En el año 2000, los paramilitares entran en el departamento de Nariño, en Colombia, y logran tener presencia en la mitad del mismo, incluyendo la frontera con Ecuador. A través de los testimonios recogidos se puede ver que la presencia paramilitar superó los límites departamentales e incursionó en el norte de Ecuador. Por ese mismo año se pudo ver una presencia en territorio ecuatoriano de parte de la guerrilla de las FARC. Esto grupo hizo algunas incursiones en las parroquias esmeraldeñas de Mataje, San Lorenzo y Selva Alegre. No se puede precisar cuál frente específico ${ }^{5}$ hacía la presencia, pero los habitantes de la región cuentan que había campamentos de entrenamiento cerca de Progreso y laboratorios de droga cerca de Pampa Real.

Con la documentación de la Corporación Nuevo Arcoíris (CNAI, documento inédito) sobre el desarrollo del conflicto colombiano en el occidente y en las fronteras, se pueden complementar los testimonios que hacen evidente durante esos primeros años del siglo XXI la presencia de las dos organizaciones armadas en la Provincia de Esmeraldas (véase figuras 1 y 2$)^{6}$.

Figura 1. Presencia de auc en Ecuador en la región norte de Esmeraldas años 2000-2002

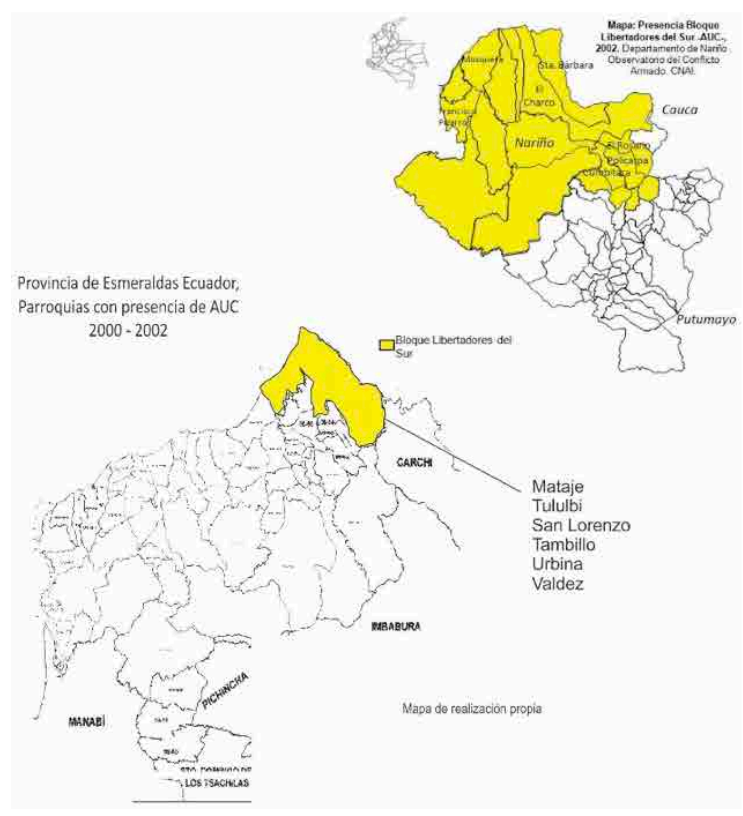

Fuente: CNAI, 2010 (elaboración propia).

5 Se puede decir que según los mapas del cnal sobre la presencia de las Farc en Nariño hacia 2002, la presencia de esta guerrilla en Ecuador pudo haber sido realizada por la Columna Daniel Aldana, pero esta información no se puede confirmar, dado que los habitantes de la región no distinguen la particularidad organizativa de los grupos armados colombianos.

6 Es muy difíil establecer una cartografía de la presencia de actores armados en la región, dado el desconocimiento de estos los habitantes de la región. En conversaciones con los habitantes no estaba claro los momentos de presencia guerrillera y paramilitar. Sumado a ello, el uso de la violencia en esta época fue dosificado, lo que dificultó el reconocimiento del actor por medio de su accionar. 
Figura 2. Presencia de las FARC en Ecuador en la región norte de Esmeraldas años 2000- 2002

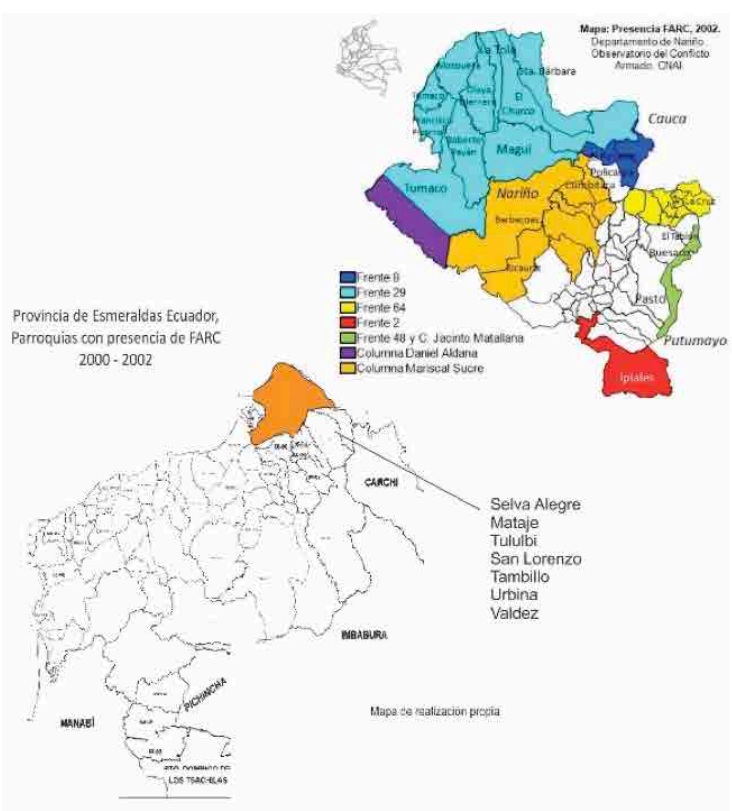

Fuente: CNAI, 2010 (elaboración propia).

La entrada de grupos paramilitares y guerrilleros en la región dio paso a un aumento de la violencia, lo cual coincidió con el aumento sustancial de los cultivos de palma. No se puede decir que las más de 3000 hectáreas de cultivo en el año 2000 fueron adquiridas a través del ejercicio de la violenta. Pero no se puede negar la coincidencia entre la movilidad que tenían los grupos armados en la región y la ubicación de los cultivos de palma. Vemos entonces que el espacio de circulación de los paramilitares es el mismo espacio donde la palma comenzó a expandirse (véase figura 3).
Figura 3. Paramilitares, año 2000-2002 y palma aceitera

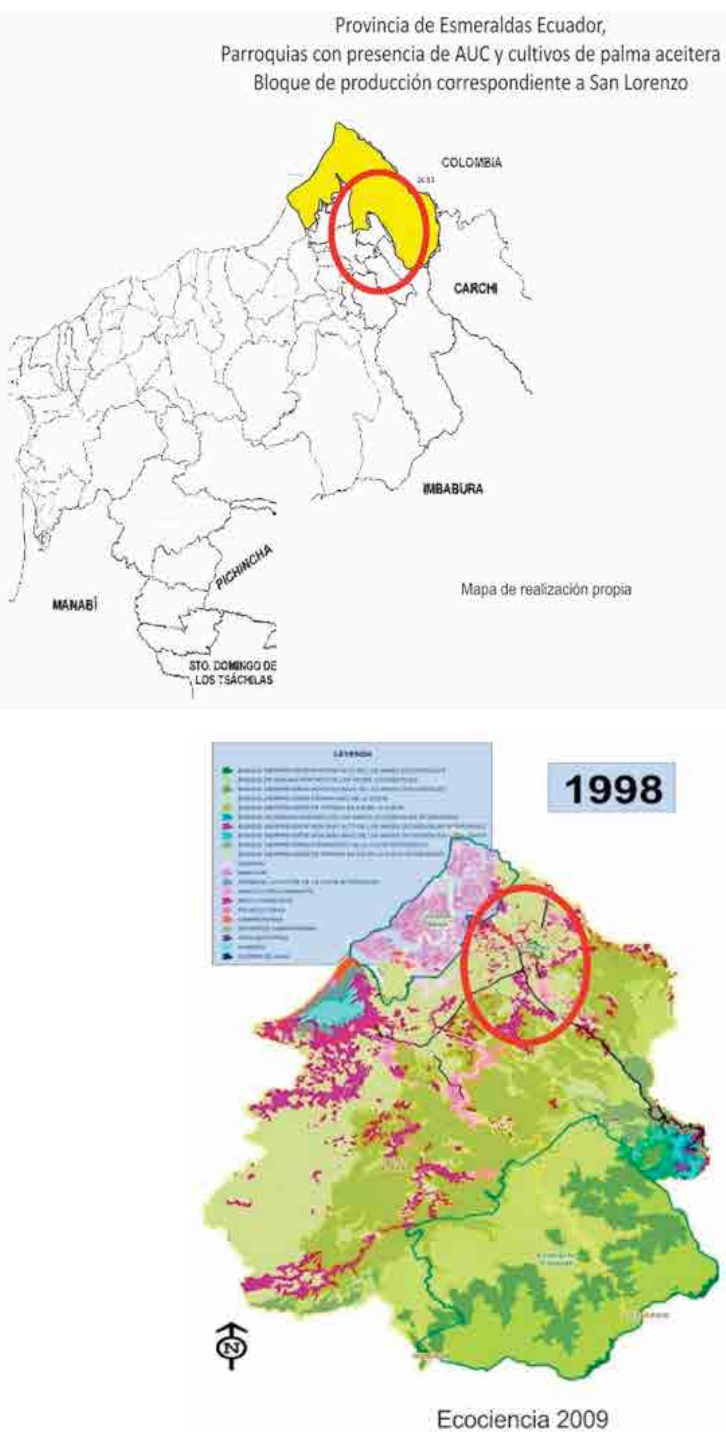

Fuente: Ecociencia, 2009 (elaboración propia, 2011). 
Como se enunció anteriormente, la dinámica económica ilegal (obtención y lavado de dólares) llevó a los grupos armados ilegales colombianos al territorio fronterizo ecuatoriano. De ahí que éstos hicieran un uso dosificado de la violencia, implementada solo en momentos necesarios; generándose así una violencia latente mas no visible.

Los años transcurridos entre 2000 y 2004 no registran una gran cuantía de homicidios ${ }^{7}$, pero ya se comenzaba a establecer la ley del silencio en la región. La dinámica del conflicto era diferenciada, varios testimonios dieron cuenta de las delimitaciones territoriales entre los grupos armados, en estos espacios confluían rutas de narcotráfico y de pertrechos de guerra. Otro elemento diferenciador fue que el paramilitarismo no hizo persecución abierta a líderes; por el contrario, con el ejercicio dosificado de la violencia, devino la construcción sistemática del miedo. Y es en este punto donde los pobladores coinciden en que la expansión de la palma se dio por vía violenta o por el miedo que se infundía a manos de sicarios y paramilitares.

\section{Consolidación del paramilitarismo: 2004-2009}

El establecimiento de los paramilitares en la región iniciado en el año 2000 y logrado a 2004 llevó a que este grupo se consolidara en la región en los años siguientes, específicamente en el año 2007. Durante ese proceso de consolidación se entiende el surgimiento de las escuelas 'sicariales' que operaron en la región entre 2004 y 2005. En dichos lugares se les tecnificaba a los grupos 'sicariales' locales en el uso de la violencia. Estas escuelas funcionaron en San Lorenzo:

Si hubo una época en que venían a perfeccionar a los de acá, los de acá mandaban a la gente y venían y perfeccionaba, pero siempre los grupos eran mixtos, hacían los contactos con la gente de allá (paramilitares colombianos) porque los de acá no conocían nada, entonces los de acá ya conocían la logística, y a su vez se perfeccionaban, cada uno hacia su parte dentro del grupo, eso fue antes de 2007. (Habitante zona norte de Esmeraldas, Ecuador, 2011).

En ese mismo año se hacen evidentes las disputas territoriales por las rutas de narcotráfico entre guerrilla y paramilitares, de ahí que estos últimos buscaron consolidar su presencia en la región haciendo alianzas con grupos locales. Una de esas bandas ecuatorianas fue la de 'Látigo', los cuales tenían control y presencia en la parroquia de Borbón. Con la presencia de los paramilitares en inmediaciones de San Lorenzo y con la banda 'Látigo' funcionando desde Borbón y con la posibilidad de replegarse en la parroquia de Limones, da cuenta de cómo en 2006 hay un control en la región por parte de estos grupos (véase figura 4), lo que permite entender el recrudecimiento de la violencia que hubo en ese año y en posteriores, como lo evidencian las figuras 5 y 6 .

Figura 4. Movilidad de paramilitares colombianos y sicarios ecuatorianos 2004

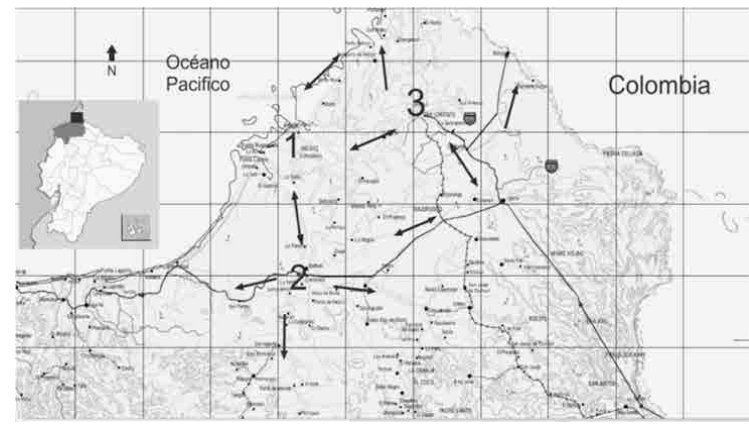

1 Limones

2 Borbón

$\rightarrow$ Rutas de movilidad: vía fluvial a Limones, San Lorenzo, Selva Alegre, y Alto San Lorenzo vía terrestre: San Lorenzo, Ciudad de Esmeraldas, Colombia.

3 San Lorenzo

Fuente: elaboración propia.

7 Durante el proceso de investigación no se pudo consolidar la tasa de homicidios. En fuentes oficiales, los datos registrados para la región de Esmeraldas comienzan en 2005. 
Figura 5. Tasas de homicidios comparativo 2004 y 2009

\begin{tabular}{|c|c|c|}
\hline Provincia & 2004 & 2009 \\
\hline Esmeraldas & 36.27 & 62.40 \\
\hline Sucumbios & 38.03 & 44.39 \\
\hline Sto. Domingo & $\ldots$ & 38.05 \\
\hline Los Ríos & 33.40 & 33.71 \\
\hline Guayas & 21.88 & 25.64 \\
\hline
\end{tabular}

Fuente: INEC, 2005, Diario expreso.

Figura 6. Homicidios provincias fronterizas 2005-2008

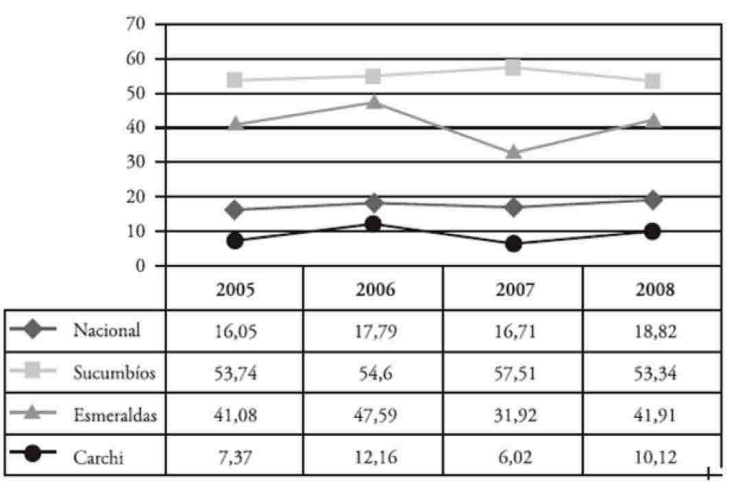

Fuente: Policía Judicial, (elaboración Víctor Llugsha).

\section{Los años de la gran violencia: 2008-2009}

Es necesario recordar que para el año 2006 en Colombia se dio la reestructuración del paramilitarismo, ello después de un proceso de desmovilización en el 2005. En 2007 se reforma la presencia del paramilitarismo en la región fronteriza ecuatoriana y entran a disputar ese espacio nuevos grupos 'sicariales' y narcotraficantes, con lo cual la violencia se recrudecería para los años siguientes. Durante el año de 2007 la presencia paramilitar se vuelve notoria y los pobladores identifican al grupo de las 'Águilas negras'. Los años 2007 a 2009 son el resultado de la transición organizativa que tuvieron los paramilitares entre 2004 y 2007.

El cambio en la organización de los grupos paramilitares repercutió en la administración de la violencia que termina en 2007 , lo que hace que 2008 y 2009 se conviertan en los años más violentos desde la entrada paramilitar. Surge entonces la pregunta: ¿qué hizo que la violencia y su ejercicio se aumentara? Fue la reorganización en la presencia del grupo en el sur de Colombia a partir de la disgregación del bloque libertadores del sur de las auc y el surgimiento de las bandas criminales: 'Águilas negras', 'los Rastrojos’ y la organización 'Nueva generación'. Esto quiere decir que la disputa territorial se comenzó a dar entre varios grupos, y no solo por el territorio, sino por el control de las rutas de narcotráfico que hay en el Pacífico ecuatoriano, que también aumentaron en el lapso de esos años (véase figuras 7 y 8). Figura 7. Actividad marítima sospechosa 2005

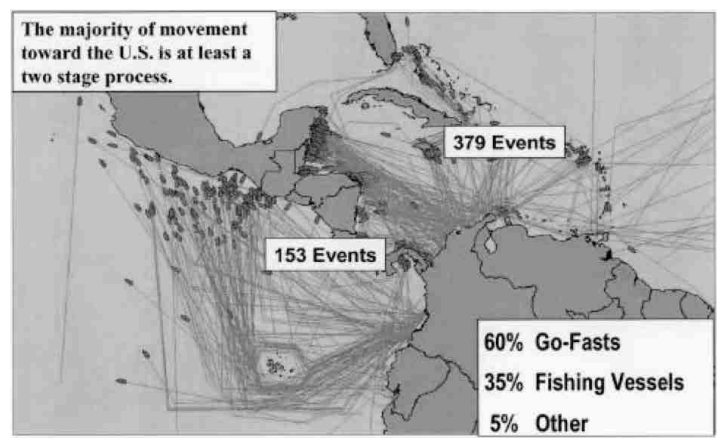

Fuente: Department of defense, Joint interagency Task Force South, 2011.

Figura 8. Actividad marítima sospechosa 2010

8 En los años anteriores la identificación de grupos armados ilegales colombianos era una tarea compleja, pero para 2007 los pobladores ya identifican claramente a las 'Águilas negras' y su asociación con la banda del 'Látigo', asociación que había comenzado con las antiguas auc. 


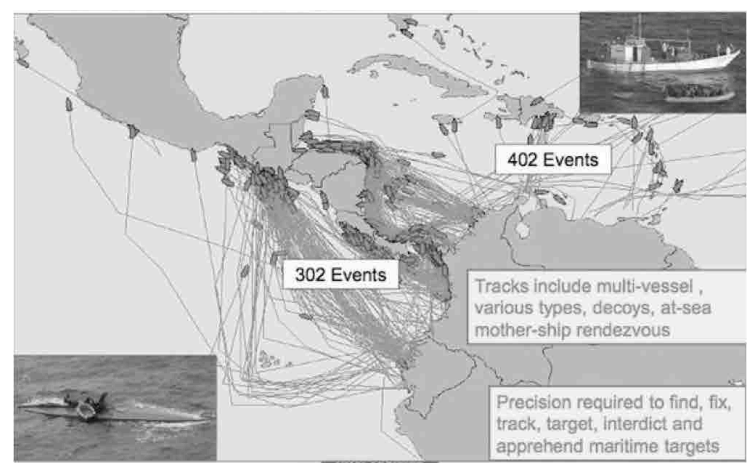

Fuente: Department of defense, Joint interagency Task Force South, 2011.

En el año 2008 hacen presencia en Esmeraldas el grupo de 'Águilas negras' y la organización 'Nueva generación', sin dejar de lado las intermitencias de las FARC y 'los Rastrojos'. Frente a este panorama, no se puede dejar de lado que el aumento de la violencia implicó el aumento del cultivo de palma aceitera. Encontramos entonces que para 2005 había 18266 hectáreas y para el año 2009 ya hay alrededor de 27000 hectáreas $^{10}$.

En el lapso de cuatro años el cultivo de palma aceitera se amplió casi en 9000 hectáreas. Los años de mayor violencia también le permitieron a la palma expandirse. En esos años, precisamente, los líderes comunales y los habitantes denunciaron que se había dado el aumento de mecanismos de presión para la venta de tierras, de ahí que los precios ofrecidos eran irrisorios: por una hectárea se ofrecían desde 200 dólares y sumada la presión 'violenta' los habitantes accedían a vender. Es en este contexto donde se entiende el aumento del cultivo de palma en los años de 2006 a 2009 y de igual manera en años posteriores (véase figura 9).

Figura 9. Cultivos de palma aceitera en la región Norte de Esmeraldas 2007-2011

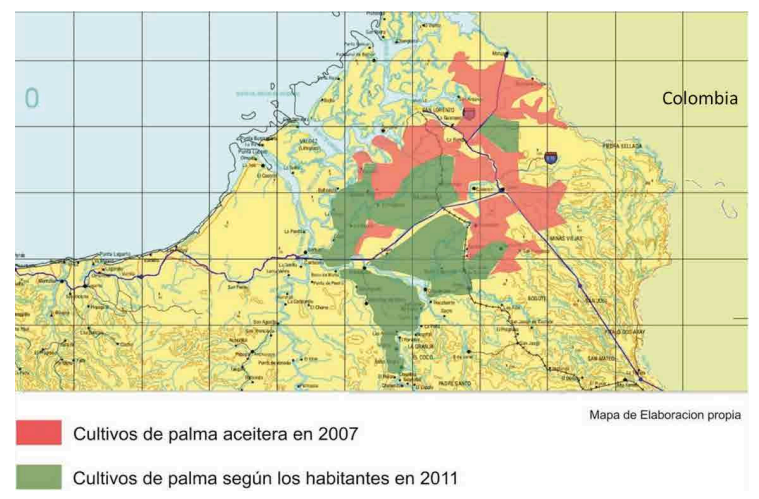

Fuente: elaboración propia.

Los modus operandi de los grupos armados ilegales y el ambiente de violencia estructural en la región devinieron en una construcción social del miedo, lo cual era reforzado por el hecho de que los objetivos de la violencia no eran claramente identificados, puesto que el asesinato en la región se realizaba por pagos, de ahí que no había una violencia directamente dirigida a líderes sociales, como sí se dio y se da en Colombia, pero en esa particularidad cualquier persona podía ser objeto de asesinato. En este escenario se puede ver el miedo de forma generalizada, y de ahí que las reivindicaciones sociales fueron menguando entre los líderes y la población en general.

El fenómeno del miedo era algo nuevo en los pobladores y en los líderes sociales. Se suma a lo anterior la sensación de vulnerabilidad: tanto líderes como pobladores sentían que no podía contar con las instituciones estatales ni con las fuerzas policiales, ya que no se tenía un conocimiento de la incidencia o los lugares donde podía tener influencia el grupo armado. Las formas de violencia convivieron y eran determinadas por los escenarios de lucha social, y es así como los grupos armados

9 Este grupo armado y narcotraficante busca extender sus redes en el Ecuador desde el año 2008, y ello se pudo verificar con las detenciones de algunos de sus cabecillas (hermanos Calle Serna) en la ciudad de Quito en marzo de 2012.

10 Fuente sobre los cultivos de palma en el Ecuador la realiza la Asociacion Nacional de Cultuvadores de Palma (Ancupa). 
ilegales seguían haciendo un uso dosificado de la misma. La vulneración a líderes se hizo de forma indirecta, como fue el asesinato de un familiar a un líder de la región, o amenazas indirectas. Un ejemplo más claro de ello fue la presencia de individuos sospechosos en reuniones sobre temas de tierras:

Cuando tú ibas a reuniones de las federaciones, tú ya sabias qué decir y qué no. Tú estabas sentado adelante y medio mirabas hacia atrás y por ahí estaba un tipo parado, o haciéndose el que anotaba, por acá otro y así. Al menos cuando se trataba de reuniones de tierra o algo así, ahí era seguro que estaban los manes. Nunca hubo una amenaza directa, solo que los manes estaban ahí, haciendo presión. (Habitante San Lorenzo, Ecuador, 2011).

Los grupos armados paramilitares que se fueron tomando la región en el lapso de diez años fueron construyendo una para institucionalidad en la región, la cual potenció formas legales e ilegales de la reproducción del capital. Estos lograron un control territorial, apresuraron el cambio en el uso del suelo en la región, con lo que se pasó de economías familiares y producción a baja escala a agroindustria palmícola. De igual manera, establecieron espacios para el desarrollo del narcotráfico y el tráfico de armas. Ante esta situación, el movimiento social se ve amenazado de una forma indirecta, la lucha por la tierra se transforma en la lucha por la soberanía alimentaria, por el derecho a la vida digna, al agua y al territorio comunitario.

El territorio comunitario de Río Santiago Cayapas comienza a ser vulnerado por todos los factores enumerados anteriormente. No solo la violencia sistemática, sino la cooptación y compra a dirigentes comunitarios permitieron que la palma ingresara en este territorio (véase figura 10).

Figura 10. Cultivos de palma aceitera dentro de la Comuna Rio Santiago-Cayapas en la región Norte de Esmeraldas 2011

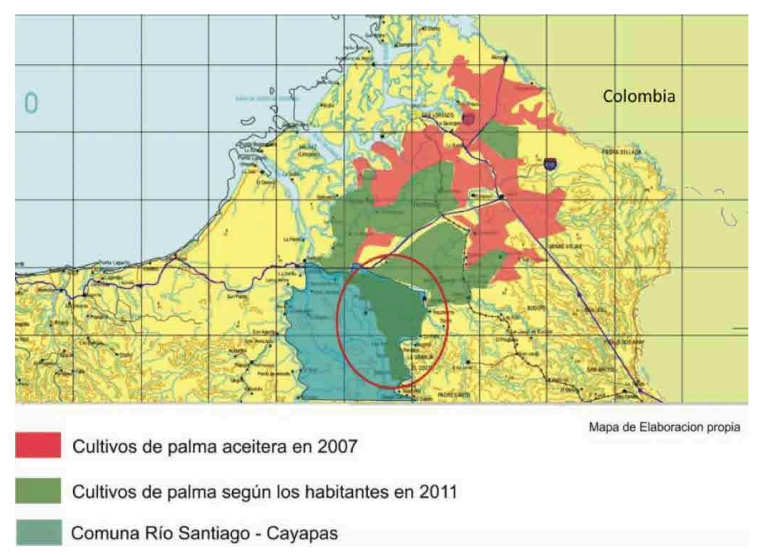

Fuente: elaboración propia.

En estos espacios del capital desposesivo, la palma fue la punta de lanza que permitió que en la región se potenciarán otras economías extractivistas, como la minería y la extracción maderera. En cuanto a la madera, era una economía que nuevamente se posicionaba en la región de forma ilegal, y la minería aparece como un nuevo fenómeno, ya que la explotación minera siempre se realizó en la región de forma artesanal; así, la entrada de retroexcavadoras y el uso de dinamita y de mercurio son prácticas que en la región no se daban en el tema minero. Este fenómeno se comenzó a desarrollar en la región con mayor ahínco desde 2008 y frente a él devino como problemática la contaminación de ríos con mercurio y otros metales pesados. Sumado a ello, el uso de agroquímicos por parte de las palmícolas llevó a que la nueva bandera del movimiento social afro fuera el agua.

Por lo tanto, bajo estas condiciones estructurales de acumulación desposesiva, violencia estructural y economías extractivistas, se puede ver que la problemática de la región solo se puede entender uniendo todos los factores. Es una problemática estructural que está ocasionando no solo el amedrentamiento de la población, sino el desplazamiento de la misma, lo que lleva a la pérdida 
de la cultura y del territorio comunal, el cual es la base de la existencia de poblaciones como afros e indígenas. De ahí que el patrón de poder racial se presenta de formas complejas en el actual momento capitalista, donde se retoman prácticas que creíamos ya extintas en las formas de explotación capitalista, como el uso de la violencia, el miedo, la amenaza, el peonaje y, por qué no, una nueva forma de esclavismo.

El racismo se potencia de diferentes maneras, donde el articulador es la violencia estructural, la cual se consolida en detrimento de las prácticas de vida ancestrales. La palma aceitera representa la fase más criminal del capital, lo que permite ver que la raza sigue siendo la matriz dinamizadora del capitalismo en su forma más desposesiva y criminal. Esta fase capitalista golpea directamente las formas organizativas alternativas y contrahegemónicas al capitalismo, por lo que las nuevas luchas sociales son por la vida, por el agua, por la cultura, por las condiciones más básicas de la existencia humana, que no son tenidas en cuenta por el capitalismo y su patrón de poder racial colonial.

\section{Referencias}

Arboleda, M. (2005). El contexto histórico y contemporáneo de la crisis ambiental en Esmeraldas. En E. Hanekamp, Quién conspira contra el ambiente. Quito: Abya Yala.

Ávila, A. (año). Conflicto armado en Nariño reconfiguración del poder regional de los actores armados, Bogotá: Corporación Nuevo Arcoíris.

Avila, A. (Ed.). (2012). La frontera caliente entre Colombia y Venezuela. Colombia: Editorial Debate.

Carrión, F., \& Espin, J. (Coords.). (2011.). Relaciones Fronterizas: Encuentros y Conflictos. Quito: FLACSO.

Carrión, F. (S.f.). La violencia en Ecuador. Recuperado de http://www.flacso.org.ec/ docs/artvioecu.pdf

Escobar, A. (1998). The "Problem of Nature" Revisited: History and Anthropology.
Recuperado de http://aescobar.web.unc.edu/ files/2013/09/arturoreview.pdf

Escobar, A. (2008). Territories of difference: place, movements, life, redes. Durham: Duke University.

Estrada, J. (2008). Capitalismo criminal: ensayos críticos. Bogotá D.C.: Universidad Nacional de Colombia.

Espín, M. J. (2011). La problemática de la violencia y el respeto a la vida en la frontera norte. En F. Carrion y J. Espin (coords.), Relaciones Fronterizas: Encuentros y Conflictos. Quito: FLACSO,

Gayraud,J. (2005).El G9 de las mafias en el mundo: geopolitica del crimen organizado. Barcelona: Tendencias.

Forgione, F. (2010). Mafia export: Como la 'ndrangheta, la cosa nostra y la camorra han colonizado el mundo. Barcelona: Anagrama.

FLACSO. (2010). Boletin ciudad Segura, (38). Ecuador. Recuperado de http://repositorio. flacsoandes.edu.ec/bitstream/10469/6320/2/ BFLACSO-CS38.pdf

Grosfoguel, R. (2006). Del final del sistema-mundo capitalista hacia un nuevo sistema histórico alternativo: la utopística de Immanuel Wallerstein. Revista Nomadas, (25). Colombia: Universidad Central.

Harvey, D. (2007). Espacios del capital: hacia una geografia critica. Madrid: Akal.

Harvey, D. (1998). La condición de la postmodernidad. Buenos Aires: Amorrortu.

Harvey, D. (2007). El nuevo imperialismo. Madrid: Akal.

Harvey, D. (2005). El nuevo imperialismo: Acumulación por desposesión. En Socialist

Register. Buenos Aires: Clacso.

Hazelwood, J. (2010). Más allá de la crisis económica: CO2lianismo y geografías de la esperanza. Revista Iconos, (36).

Jaramillo, M., et al. (1981). Diagnóstico socioeconómico de la provincia de Esmeraldas. Otávalo, Ecuador: Instituto Otavaleño de Antropología.

Llugsha, V. (2011). Gobernanza de la seguridad ciudadana en la frontera norte del Ecuador. En Carrion y Espin, Relaciones fronterizas: encuentros y conflictos. FLACSO: Ecuador. 
Medina Gallego, C. (2008). El narco-paramilitarismo Lógicas y procesos en el desarrollo de un capitalismo criminal. En J. Estrada (coord.), Capitalismo criminal: ensayos críticos. Bogotá D.C.: Universidad Nacional de Colombia.

Pucese. (2011). Análisis de los impactos y conflictos provenientes de la actividad aurifera en la zona norte de la provincia de Esmeraldas para la construcción de paz en las comunidades afectadas. Centro de Investigación y Desarrollo, Pontificia Universidad Católica del Ecuador Sede Esmeraldas.

Quijano, A., \& Wallerstein, I. (1992). Americanity as a concept, or the Americas in the modern world - system. Duke.

Quijano, A. (2000). Colonialidad del poder, eurocentrismo y América Latina. En E. Lander, La colonialidad del saber: eurocentrismo y ciencias sociales. Perspectivas latinoamericanas. Caracas: Faces-UVCIESALC.

Roa, I. (2011). El desborde de la violencia: raza, capital y grupos armados en la expansión transnacional de la palma aceitera en Nariño y Esmeraldas [Tesis para optar por el grado de magíster]. FLACSO Ecuador, Quito.

Wallerstein, I., \& Balibar E. (1991). Raza, Nación y Clase. Madrid: IEPALA. 